Island Studies Journal, Vol. 2, No. 2, 2007, pp. 193-208

\title{
Archipelagos and Political Engineering: The Impact of Non-Contiguity on Devolution in Small States
}

Dag Anckar

Åbo Akademi University

Finland

dag.anckar@abo.fi

\begin{abstract}
Political architecture differences have only seldom been explained in the political science literature by reference to physical factors like size and geography. Correcting this neglect while focusing on microstates and especially on archipelago geographies, this article aims at uncovering the impact of geographical non-contiguity on political institution-building. Three separate devices for power devolution - federalism, bicameralism and assembly quotas - perform as dependent variables, and the guiding hypothesis is, for each device, that the device is implemented among archipelagos to a higher extent than among contiguous entities. Although there are marked differences between devices, the findings in general support the belief that territorial non-contiguity is more likely to foster power devolution. The findings also survive controls that investigate the impact of contesting factors.
\end{abstract}

Keywords: archipelagos, contiguity, devolution, islandness, political institution

Copyright @ 2007 Institute of Island Studies, University of Prince Edward Island, Canada.

\section{Introduction}

Countries differ in terms of politico-institutional architecture, and the differences have been explained in the literature by reference to a multitude of factors and country characteristics. While some regard political institutions and devices as "problem-solvers" (Laponce \& Saint-Jacques, 1997), designed to manage and ward off problems that emanate from the social structure of society, others pay more attention to cultural factors, such as colonial heritage (e.g. Anckar, 2004), or to demographic factors, like the ethnic composition of the population (e.g. Lijphart, 1977). One rather neglected approach is to focus upon the impact of physical factors like size and geography; this article is a contribution to this particular area of research. Specifically, with the term non-contiguity meaning that the territory and population of a state is divided into two or more sections the article aims at uncovering the impact of geographical non-contiguity on the emergence of political institutions and devices for the advancement of decentralization and devolution.

By way of introduction, three specifications are in order. First, whereas the notion of noncontiguity applies to several geographic situations, such as non-contiguity with intervening bodies of water, and non-contiguity with intervening landmasses (Merrit, 1969:238-9), this research is expressly about insular non-contiguity, this term denoting geographical 
divisions within island states and referring, therefore, to archipelago geographies. Second, the research is about microstates only. This is because insular non-contiguity is a phenomenon that is to a large extent empirically linked to the microstate world, and because a preoccupation also with the few larger archipelagos would introduce in an awkward manner the size factor in the research design. Decentralization and power devolution being usually associated with territorially larger states (Derbyshire \& Derbyshire, 1999:18), the size factor must be controlled for, and focusing on similar-sized entities only is the obvious method for achieving this goal. In other words, the focus on microstates is empirically valid and methodologically essential. Third, the research is theory-driven. It departs from, as well as investigates, the notion that archipelago systems have special characteristics that create predispositions to autonomy and power devolution.

Several separate as well as inter-connected considerations motivate this belief (Anckar, 2005:117-8). First, islandness is in itself likely to foster nationalism, and decentralization emerges in archipelagos as a powerful means for managing the mental distances between islands that follow in the wake of nationalist tune (e.g. Short, 1987; Henningham, 1995:5270). Second, the sources and origin of island nationalism are also likely to foster a desire amongst islanders to maintain their own traditions and identities, and devices for autonomy and devolution stand out as means for accommodating such aspirations (e.g. Ravuvu, 1992; LiPuma, 1995; Virelala, 1995). Third, as fragmented and distant geographies render difficult a manageable centralization of government and administrative power, practical, logistical and organizational considerations alone are likely to elicit the benefit of decentralization and devolution in archipelagos. Furthermore, islands are likely to appear different and singular in the minds of mainlanders as well as islanders, the former taking in a disposition to regard and treat island territories as distinct administrative units, and the latter having a vision to see themselves in like manner as a distinct unit (Baldacchino, 2000:72). From these factors, then, may be derived the expectation that institutional devices for decentralization and devolution are widely spread in the context of archipelagic islandness. In consequence, the leading hypothesis that guides this research is that whereas small size in itself discourages decentralization, this relation is tamed by an archipelagic geography that, instead, fosters decentralization.

The article has five sections. Following the brief introduction above, a second section identifies the microstates that are included in the research; this section also provides data on some central characteristics of these states. Next, empirical findings and patterns are reported in the following two sections. The first explains the methodology and focuses on three separate devices for decentralization and power devolution; the second produces overarching results, and also includes controls for the impact of two theoretically important contesting factors. Finally, a fifth section provides a summary and a discussion of the main findings.

\section{A Population of 41 Microstates}

The concept of "microstate" is applied here to states that have one million inhabitants or less. This ceiling is widely accepted in the literature and is in fact the usual method for defining microstates in political-science studies. Still, most microstates are diminutive to 
an extent that occasions the question if this standard one million ceiling really is valid and relevant. Out of a total of 41 microstates in 2006, no less than $33(80 \%)$ report populations of 500,000 or less, while $24(60 \%)$ have populations of about 300,000 or less. It would appear, therefore, that the conventional scale is imbalanced, eight units out of ten appearing on the lower half and six units out of ten appearing on the lowest third of the scale. However, to avoid confusion and to facilitate comparisons with other microstate studies, the standard one million ceiling is nevertheless applied here.

The 41 microstates are listed in Table 1 under two main headings. The first, representing contiguity, enumerates 20 states that are either mainland states, such as Liechtenstein, or states that consist of one principal island, like Iceland. However, the most recent newcomer to this microstate camp, Montenegro, independent in 2006, is left out from the research for lack of data, as the political architecture of this new state is still a matter of consideration. The second group, representing non-contiguity, enumerates 21 states, which are classified as archipelagos. This covers, besides 16 multi-island states, five microstates that consist of two principal islands: Antigua-Barbuda, Malta (Malta and Gozo), St Kitts-Nevis, Samoa (Savaii and Upolu), and São Tomé and Príncipe. While prevailing usage reserves the archipelago concept for groups rather than pairs of islands (e.g. Hamilton-Jones, 1992: 200-1), given the theoretical points of departure for this study, the distinction between noncontiguous island states that consist of two separate parts and non-contiguous island states that consist of many parts becomes meaningless. In fact, experiences from the political life of at least Antigua-Barbuda (e.g. Richardson, 1992:187-8), St Kitts-Nevis (e.g. Anckar \& Bartmann, 2000:28-9), and São Tomé and Príncipe (Hodges \& Newitt, 1988:110) certainly suggest the existence of even severe and devolution-promoting antagonisms between the parts of two-island states.

Table 1 provides information about the population size of each small state as at 2006, and obtained from The CIA World Factbook, accessed on January 27-30, 2007. Furthermore, the table provides information about the level of social fragmentation and the democratic status of the state in question. These characteristics will be used later in the article for control purposes. Data about fragmentation are from a fairly recent measurement of ethnic and other fragmentation in the world (Anckar et al., 2002). In this measurement, for each and every country, an index ranging from 0 to 1 is calculated, a higher value denoting a higher level of fragmentation. Separate indexes of ethnic, linguistic and religious fragmentation are given; in addition, a combined measure gives an index of total fragmentation which comes to use in this research. Calculations of this total index add to the value of religious fragmentation the value for ethnicity or language, whichever is higher (Anckar et al., 2002:6). As evident from the compilations, the countries differ widely in terms of this fragmentation characteristic: the measures cover a wide spectrum between homogeneity and heterogeneity. Whereas the Comoros (0.07), Malta (0.14) and Iceland (0.15) are the most homogeneous cases, Guyana (1.36), Surinam (1.51) and Vanuatu (1.80) are the most heterogeneous. 


\section{Anckar}

Table 1: The Microstates of the World, 2006: Size, Fragmentation and Political Status.

\begin{tabular}{|c|c|c|c|}
\hline \multicolumn{4}{|l|}{ Contiguous Microstates (=20) } \\
\hline Mainland States (=13): & Population Size: & Fragmentation: & Status: \\
\hline Andorra & 71,000 & 0.67 & democracy \\
\hline Belize & 288,000 & 1.31 & democracy \\
\hline Brunei & 379,000 & 1.02 & non-democracy \\
\hline Djibouti & 486,000 & 0.92 & non-democracy \\
\hline Equatorial-Guinea & 540,000 & 0.51 & non-democracy \\
\hline Guyana & 767,000 & 1.36 & democracy \\
\hline Liechtenstein & 34,000 & 0.80 & democracy \\
\hline Luxembourg & 474,000 & 0.65 & democracy \\
\hline Monaco & 32,000 & 0.87 & democracy \\
\hline Qatar & 885,000 & 0.91 & non-democracy \\
\hline San Marino & 29,000 & 0.37 & democracy \\
\hline Surinam & 439,000 & 1.51 & democracy \\
\hline Vatican City & 1,000 & NA & non-democracy \\
\hline \multicolumn{4}{|l|}{ One-Island States (=7): } \\
\hline Barbados & 280,000 & 0.87 & democracy \\
\hline Cyprus & 784,000 & 0.79 & democracy \\
\hline Dominica & 69,000 & 0.55 & democracy \\
\hline Grenada & 90,000 & 0.80 & democracy \\
\hline Iceland & 299,000 & 0.15 & democracy \\
\hline Nauru & 13,000 & 1.17 & democracy \\
\hline St Lucia & 168,000 & 0.41 & democracy \\
\hline \multicolumn{4}{|l|}{ Archipelagos (=21) } \\
\hline \multicolumn{4}{|l|}{ Two-Island States (=5): } \\
\hline Antigua-Barbuda & 69,000 & 0.45 & democracy \\
\hline Malta & 400,000 & 0.14 & democracy \\
\hline St Kitts-Nevis & 39,000 & 0.65 & democracy \\
\hline Samoa & 177,000 & 0.65 & democracy \\
\hline São Tomé and Príncipe & 193,000 & 0.56 & democracy \\
\hline \multicolumn{4}{|l|}{ Multi-Island States (=16): } \\
\hline Bahamas & 304,000 & 0.84 & democracy \\
\hline Bahrain & 699,000 & 1.09 & non-democracy \\
\hline Cape Verde & 421,000 & 0.46 & democracy \\
\hline Comoros & 691,000 & 0.07 & non-democracy \\
\hline Federated States of Micronesia & 108,000 & 0.75 & democracy \\
\hline Fiji & 906,000 & 1.12 & non-democracy \\
\hline Kiribati & 105,000 & 0.58 & democracy \\
\hline Maldives & 359,000 & 0.66 & non-democracy \\
\hline Marshall Islands & 60,000 & 0.25 & democracy \\
\hline Palau & 20,000 & 1.13 & democracy \\
\hline St Vincent and the Grenadines & 118,000 & 0.90 & democracy \\
\hline Seychelles & 81,000 & 0.37 & non-democracy \\
\hline Solomon Islands & 552,000 & 1.34 & non-democracy \\
\hline Tonga & 115,000 & 0.42 & non-democracy \\
\hline Tuvalu & 12,000 & 0.20 & democracy \\
\hline Vanuatu & 209,000 & 1.80 & democracy \\
\hline
\end{tabular}


The question whether or not individual states are democracies is approached through freedom ratings provided by the Freedom House organization. Based on surveys provided by regional experts, consultants and human rights specialists as well as fact-finding missions and public sources, Freedom House has monitored since 1972 the progress and decline of political rights and civil liberties in all the nations of the world and in related territories. In essence, the units are rated on 7-category scales for political rights and civil liberties, and then, on the basis of these ratings, placed into one of the categories of "Free", "Partly Free" and "Not Free". Here, as in several other contexts and investigations (e.g. Lijphart, 1999), the category of "Free" is perceived and used as a convenient shortcut for identifying democratic units. The actual ratings indicate the prevalence of the democracy category, and they certainly support the view, frequently denoted in the literature, of small size standing out as an enabling environment for democratization (e.g. Diamond \& Tsalik, 1999; Ott, 2000; Anckar, 2002; Srebrnik, 2004). Out of a total of 41 microstates, 29 (71\%) are deemed to be democratic.

\section{Three Devices}

To determine the extent to which the difference between contiguous and archipelagic geographies bears impact on political architecture, the occurrence of 3 politico-institutional devices for promoting devolution in microstates is investigated. These devices are: decentralization, bicameralism and assembly quotas. For each device, the guiding hypothesis is that the device is implemented among archipelagos to a higher extent than among contiguous entities. (The specific rationales for these assumptions are explained below.) The operational clarification of the extent to which contiguous and non-contiguous microstates implement these devices builds upon a trisected point index, which awards two devolution points for the implementation of a device that carries into full effect a devolution of power, one point for the implementation of a device that carries into partial effect a devolution of power, and withholds points for devices that do not signify a contribution to devolution and power-sharing. Again, the rationales for the ensuing classifications are explained below.

Territorial Organization. The two basic solutions to the territorial organization of power are, of course, unitary and federal government. In unitary systems, sovereignty resides solely with the centre; such systems, then, do not contribute to devolution, and they do not receive points in the following classifications. Federalism, on the other hand, divides sovereignty between central and provincial governments and is therefore in full agreement with principles of devolution and autonomy. In the intermediate category are here classified states that are not strictly federal, but still have decentralized forms of government: these may be named "unitary states with decentralized features" (Derbyshire \& Derbyshire, 1999: 17-23). They are given one point. Examples are: Solomon Islands and Vanuatu (with provincial assemblies and regional councils respectively); Tuvalu (where each inhabited atoll has its own elected Island Council); and São Tomé and Príncipe, where Príncipe enjoys internal autonomy. As evident from Table 2, the vast majority of microstates, (31 out of 41), have not established and implemented a division of sovereignty. Six microstates are unitary but have decentralized features; four microstates are federal. These federal microstates, which indeed put the popular assumption of a link 
between big size and federalism to a test, are: Palau, Comoros, Federated States of Micronesia and St Kitts-Nevis (Anckar, 2003). They represent different varieties of federalism, and the Palau variety resembles in fact a local government arrangement (Anckar, 2003:118-9). The small number of devolution cases notwithstanding, the distribution of these cases extends powerful support to the idea of a link between geography and devolution. With the exception of mainland San Marino, which operates a system of nine, partially self-governing castles (Duursma, 1994:221-2), all the remaining nine devolution cases are archipelagos (Anckar, 2005:113). In other words, it is indeed the case that smallness generally encourages unitary government; while small archipelago geographies foster decentralization.

Bicameralism. Countries which apply unicameralism and therefore reject the possibility of power-sharing that is inherent in the bicameral model are classified here in the nondevolution category and do not receive points. As for bicameral countries, a distinction is introduced that observes and builds upon the two main arguments in favour of a dual legislative system. Whereas a bicameralism that aims at resolving regional and other distinct interests is classified as a devolution device and therefore receives two points, a bicameralism that aims at general moderation only is classified as an intermediate device which receives one point. The operational method for deciding separate country classifications is about recruitment: whereas regional interest chambers are formed by methods that emphasize a regional basis, moderation chambers are formed by methods that give priority to an overall representative basis. The findings are, again, that the device is rare among microstates, no less than 33 of the 41 cases having unicameral legislatures. Only one state, namely tiny Palau, has opted for a regionally defined bicameralism, whereas seven states have introduced a weaker form of bicameralism. Almost all these cases are former British colonies in the Caribbean hemisphere and this pattern certainly suggests that bicameralism among microstates is a Commonwealth category and a reflection of the British political model (Anckar, 1998). In terms of geography effects on devolution, the general finding is much different than the one that concerned the decentralization device. No real differences can namely now be detected between contiguous and archipelago units. Four out of 20 contiguous units and four out of 21 archipelagos have installed the bicameral device. Given this similarity in pattern and given also the general absence of a regionally defined bicameralism, it would appear, contrary to expectations, that the use of bicameralism is not related to geography categories. 


\section{Table 2: Devolution point scores among contiguous and archipelagic microstates.}

\section{Contiguous Microstates (=20)}

Decentralization Bicameralism Quotas Total

Mainland States:

Andorra

Belize

Brunei

Djibouti

Equatorial-Guinea

Guyana

Liechtenstein

Luxembourg

Monaco

Qatar

San Marino

Surinam

Vatican City

\section{Devolution Points}

One-Island States:

Barbados

Cyprus

Dominica

Grenada

Iceland

Nauru

St Lucia

\begin{tabular}{|c|c|c|c|}
\hline 0 & 0 & 0 & 0 \\
\hline 0 & 1 & 0 & 1 \\
\hline 0 & 0 & 0 & 0 \\
\hline 0 & 0 & 2 & 2 \\
\hline 0 & 0 & 2 & 2 \\
\hline 0 & 0 & 2 & 2 \\
\hline 0 & 0 & 0 & 0 \\
\hline 0 & 0 & 0 & 0 \\
\hline 0 & 0 & 0 & 0 \\
\hline 0 & 0 & 0 & 0 \\
\hline 1 & 0 & 0 & 1 \\
\hline 0 & 0 & 0 & 0 \\
\hline 0 & 0 & 0 & 0 \\
\hline 0 & 1 & 0 & 1 \\
\hline 0 & 0 & 2 & 2 \\
\hline 0 & 0 & 2 & 2 \\
\hline 0 & 1 & 0 & 1 \\
\hline 0 & 0 & 0 & 0 \\
\hline 0 & 0 & 0 & 0 \\
\hline 0 & 1 & 0 & 1 \\
\hline 1 & 4 & 10 & 15 \\
\hline
\end{tabular}

Total:

Archipelagos (=21)

Two-Island States:

Antigua-Barbuda

Malta

St Kitts-Nevis

Samoa

São Tomé and Príncipe

Multi-Island States:

Bahamas

Bahrain

Cape Verde

Comoros

Federated States of Micronesia

Fiji

Kiribati

Maldives

Marshall Islands

Palau

St Vincent and the Grenadines

Seychelles

Solomon Islands

Tonga

Tuvalu

Vanuatu

$\begin{array}{llll}0 & 1 & 0 & 1 \\ 0 & 0 & 0 & 0 \\ 2 & 0 & 2 & 4 \\ 0 & 0 & 1 & 1 \\ 1 & 0 & 0 & 1\end{array}$

Total:

13

33 
Assembly Quotas. In several countries a certain number of parliamentary seats are reserved for designated organizations or interest groups. Examples from the microstate camp are Cape Verde, inviting diaspora residents to send deputies to the National Assembly (Hawthorne, 1999:186), and Samoa, where two out of 49 representatives are elected to Parliament to represent non-Samoans and part-Samoans (So’o, 2001:783). Introducing such assembly quotas implies, in principle at least, a greater extent of devolution, powersharing and inclusiveness than is evident from election results alone. The use of quota is therefore here taken to represent a devolution-promoting deviation from majority rule. In consequence, countries that do not apply the assembly quota device do not receive devolution points. Concerning countries that make use of the device, a distinction is made between broad and narrow quota magnitudes. Countries that distribute less than $10 \%$ of the assembly seats by means of quotas are given one point, whereas countries that distribute $10 \%$ or more of the seats are given two points. Again, the large majority of the states, 27 out of 41, have abstained from introducing the device. As noted elsewhere (Anckar, 2006:200-1), most microstate cases that have installed the device operate broad magnitudes. The quota device contributes clearly more than the other devices to the total yield of the contiguous countries, producing two thirds of the total points for this group. Still, contiguous countries are inferior to the archipelagos, nine out of 21 archipelagos receiving points as against five out of 20 contiguous states. Again, therefore, the leading impression is one of a non-contiguous geography promoting devolution and thus making a difference, albeit a fairly small one. Closer looks at the separate cases at hand support this impression. Whereas no less than seven out of the nine archipelago cases make use of the quota device explicitly to ensure a representation for specific regions or ethnic interests, the pattern is much different among contiguous states. In fact, the only contiguous case that clearly recognizes a regional or an ethnic interest is bi-communal Cyprus, which reserves a substantial portion of the parliamentary seats for Turkish members. As is well known, these seats have never been taken up (Legg, 1999:270).

\section{A Bird's Eye View}

Since the units have been classified along three dimensions, the classifications on each dimension giving each unit none, one, or two points, the maximum score for an individual unit is six points. Therefore, based on performance, the units may be placed on a scale running from none to six points, and this is done in Table 3. A conspicuous feature from this Table is a scantiness of registrations. The two categories that represent the most widespread use of devolution devices remain empirically empty; in contrast, the two categories that represent a very restricted or even non-existent use of the same devices are richly populated, containing some two thirds of the microstates. The overarching finding, then, which is by no means unexpected and was clearly visible already in the foregoing review of individual devices, is that the microstate camp does not engage forcefully in matters of decentralization and devolution. As a general rule, although certainly one with exceptions, small units do not establish and maintain politico-institutional mechanisms that would serve such ends. The hypothesis that smallness discourages decentralization is certainly confirmed in this study. 
Table 3: Number of contiguous and archipelagic microstates in seven devolution point categories.

\begin{tabular}{|c|c|c|c|c|c|c|c|}
\hline \multirow[t]{2}{*}{ Microstates } & \multicolumn{7}{|c|}{ Devolution Points } \\
\hline & 6 & 5 & 4 & 3 & 2 & 1 & $\mathbf{0}$ \\
\hline Contiguous & - & - & - & - & 5 & 5 & 10 \\
\hline Archipelagos & - & - & 3 & 1 & 5 & 8 & 4 \\
\hline Total & - & - & 3 & 1 & 10 & 13 & 14 \\
\hline
\end{tabular}

Still, within contiguous units as well as archipelagos there is a noticeable variation, some countries promoting measures of devolution more than others. However, the contiguous universe is clearly more condensed: Djibouti, Equatorial-Guinea, Guyana, Cyprus and Dominica score two points each, and all the remaining 15 cases score either one point or no points. It is a notable feature that all 10 points scored by the above five cases originate from applications of the assembly quota device, which is multi-functional and does not always reflect a genuine interest in power devolution and the accommodation of designated interests (Anckar, 2006:208). This feature clearly serves to weaken still more in this analysis the contribution of contiguity to devolution practices. Concerning archipelagos, the scores vary between zero and four points: three of the four federal microstate cases, namely Palau, Micronesia and St Kitts-Nevis, secure places among the top proponents of devolution; and six more cases, three of which are from the Pacific area, score two points or more.

While it is true that smallness discourages decentralization, it is equally true that this association disappears when and if smallness has the form of an archipelagic geography. Indeed, an inspection of Table 2 and Table 3 indicates that a strong case can be made for the belief that an archipelagic geography moulds political institutions. Several separate quantitative observations substantiate this conclusion. First, the 20 contiguous units score a total of 15 devolution points and the 21 archipelagos score a total of 33 points; in consequence, contiguous units score on average 0.75 points as against 1.57 points by archipelagos. Second, on average the microstates score 1.17 points; of the altogether 14 cases which report higher than average scores, no less than nine are archipelagos. Third, whereas half of the contiguous countries do not score devolution points at all, the same is true of only four out of 21 archipelagos. Finally, only five out of 41 microstates make use of two out of the three devolution devices, and these five states are all archipelagos. In sum, being an archipelago makes a difference, and this difference is about a broader involvement in institutions and practices of decentralization and devolution. 


\section{Possible Impact of Other Factors}

However, before the hypothesis that insular non-contiguity fosters autonomy and power devolution can be accepted, the findings must survive controls that aim at investigating the impact of other factors that may be equally probable causes of devolution and thereby challenge the explanatory power of the geography factor. One such factor is ethnic and social fragmentation, the contending assumption being that fragmentation fosters devolution. This heterogeneity hypothesis is certainly reasonable, as it makes sense to assume that countries that are characterized by internal diversity and fragmentation have a special need to overcome these traits by means of decentralization and power devolution. When attempting now to establish the prevalence of geography or fragmentation, the task becomes one of comparing homogeneous and heterogeneous units while controlling for geography, and comparing contiguous units and archipelagos while controlling for fragmentation. These comparisons are carried out in Table 4 and are based on the data for microstate social fragmentation that were inserted in Table 1. The analysis proceeds from a dichotomous and somewhat arbitrary but still reasonable classification that depicts countries which have a total fragmentation of less than 0.9 as homogeneous units. Heterogeneous countries, on the other hand, have a total fragmentation of 0.9 or more. Heterogeneity being the crucial factor in this control exercise, the threshold is high enough to guarantee that the group of heterogeneous countries $(\mathrm{N}=13)$ really includes relevant cases.

Table 4: Controlling for heterogeneity and democracy. Average devolution points in groups of units.

\begin{tabular}{|lccc|}
\hline & Contiguous units & Archipelagos & All \\
Heterogeneous units & 0.7 & 1.8 & 1.2 \\
Homogeneous units & 0.8 & 1.6 & 1.2 \\
& Contiguous units & Archipelagos & All \\
Democratic units & 0.7 & 1.6 & 1.2 \\
Non-democratic units & 0.8 & 1.4 & 1.2 \\
\hline
\end{tabular}

The figures from Table 4 show, first, that there is no difference whatsoever in terms of devolution between heterogeneous and homogeneous countries; this certainly suggests that the devolution differences have to do with geographical rather than social fragmentation. The figures also show that there is, within both groups, an evident difference between contiguous units and archipelagos. Inversely, within the group of contiguous units as well as within the archipelagos, no difference worth mentioning can be detected between fragmented and homogeneous units. In other words, patterns of social fragmentation cannot challenge the explanatory power of the contiguity notion. Contiguous units behave as a rule in one manner, be they fragmented or not, and archipelagos behave as a rule in a different manner, be they fragmented or not. Observations on individual countries serve to 
verify this impression. Some fragmented countries indeed advance devolution; examples are: federal and bicameral Palau; Fiji, which maintains for reasons of ethnic conflict a most complicated electoral and quota system (Hartmann, 2001:647-51); and Djibouti, which operates a gender-based quota system (Htun, 2004:452). On the other hand, some fragmented countries like Bahrain and Nauru do not engage in devolution. In like manner, whereas some homogeneous countries advance devolution, others do not. In the first group are, for instance, federal Comoros and federal St Kitts-Nevis; in the second group are, for instance, Iceland, Luxembourg and Malta.

A second contesting factor that must be investigated is the democracy status of the states involved. True, a quick glance at the globe questions the overall relevance of this factor, as there are indeed in the world several cases of non-democracies which retain mechanisms for decentralization and power devolution (e.g. Karvonen, 2003:26-31; Hague \& Harrop, 2004:245-6). Still, it is only natural to believe that power devolution thrives more fully in a democratic, responsive, and open environment than in the closed and inhospitable quarters of non-democracies. In short, more than non-democracies, democracies may be expected to recognize, respect and accommodate political, social and cultural shadings and disparities (Anckar, 2005:116); it therefore makes good sense to consider and control for the possibility that microstate decentralization and devolution result from distinctions of democracy rather than geography.

Again, the outcome of this control is reported in Table 4 which utilizes the dichotomized microstate democracy data that were inserted in Table 1. Again, the verdict is straightforward. The relation between geography and devolution is a survivor, as the relation appears within the group of democracies as well as within the group of nondemocracies, the democracy distinction having in itself no bearing whatsoever on the relation. Also, within contiguous countries there is no difference in terms of devolution between democracies and non-democracies, and within archipelagos, there is no marked difference between democracies and non-democracies. Again, contiguous units behave as a rule in one manner, be they democratic or not, and archipelago units behave as a rule in a different manner, be they democratic or not. Observations on individual countries support the view that democracy does not structure systematically the property space. Some democracy units, like Palau, Guyana, or Kiribati are in favour of devolution, whereas others, like Andorra, Malta or the Marshall Islands, are not. On the other hand, some nondemocracy units, like Comoros, Djibouti and Fiji, are in favour of devolution, whereas others, like Brunei and the Seychelles, are not.

\section{Conclusion}

The relationship between geography and politics works in two analytical directions. On the one hand, as political decisions are transactions between the political system and its many environments, the decisions may affect in a variety of ways the physical and human prerequisites of politics (Easton, 1965:345-8). In political science, however, the role of geography is to explain rather than to be explained, and it is for a geography-inspired political science an important task to find out to what extent geographical factors provide and create opportunities, which affect the nature, orientations and institutional structures of 
societies (e.g. Gottmann, 1980). Indeed, during earlier decades proponents of geopolitical analysis even cherished the belief that the geographical settings of states form the ultimate causal factor in politics. Today, of course, such a geographical determinism is generally considered to be inadequate as a social theory of politics and it was declared in an influential study, decades ago, "a pseudoscience erecting the factor of geography into an absolute” (Morgenthau, 1966:153). In fact, in the course of a pendulum swing from one extreme to another, geography emerges today as a rather neglected angle of approach for explaining political life.

Still, as evident also from this research, geography is by no means an insignificant source of political design. In his detailed review of small island insularity, Stephen Royle maintains that most insular states are archipelagos and that small islands can in such circumstances have the same dependent relationship with the power centre of its insular state as an offshore continental island has with its mainland power base (Royle, 2001:162). While this may be true, it is however equally likely that archipelago islands, precisely because they are secluded members of groups, conjure up - as well as are entrusted with institutional arrangements that respect and accommodate their individuality. Indeed, although there is little reason to dispute the general validity of the statement that unitary structures are the norm in smaller systems, this research has suggested that deviations from this norm occur, and are frequently evoked by an archipelagic geography. The research has even suggested a sort of semi-linear relationship, the implication of which is that the extent of devolution is likely to increase as the extent of islandness and insular non-contiguity is growing. It is an interesting observation from the material at hand that one-island states show a greater average amount of devolution points than mainland states, and that archipelagos, in turn, show a greater average than one-island states. The actual average figures are 0.7 for mainland states, 1.0 for one-island states, and 1.5 for archipelagos.

The core of island studies has been said to be the constitution of islandness and its possible influence and impact on areas handled by traditional subject disciplines and issues (Baldacchino, 2006:9-10). From this perspective, emerges a conceptualization of islandness as a sort of intervening variable, and as this present political-science inspired exercise in island studies goes a long way to explain the spotty and even somewhat queer occurrence of decentralization and devolution devices among very small units, the study certainly answers well in terms of ambition and outcome to the above characterization. Indeed, the particular form of islandness that assumes an archipelagic form stands out as a powerful prediction of when small size combines with decentralization and devolution. When this archipelagic form is absent, only in one case out of twenty was there a form of devolution; on the other hand, when the form does exist, it almost always entails devolutionary measures of some kind. True, there are exceptions to this rule, as a small handful of archipelagic microstates have refrained altogether from the use of devolution devices; in these cases, then, other factors have neutralized any pressures on autonomy development that geography may have exerted. However, the overarching pattern that has come to the fore in this investigation designates an archipelagic geography as a powerful intervening circumstance that motivates small units to adapt methods and devices that thrive more naturally in larger-sized countries and entities. 
Concerning the significance of these methods and devices, this study has uncovered some palpable differences. Whereas observations on the use of the decentralization device are in very good agreement with the leading hypothesis of an archipelago impact, observations on the use of the bicameral device rather serve to call the hypothesis in question. Observations on the use of the quota device again appear to corroborate the hypothesis. These differences are most probably outcomes of two factors. First, the devices differ in the extent to which they are multifunctional: whereas decentralization is almost by definition about establishing autonomy arrangements, the use of the bicameralism and quota institutions may in separate cases flow from other motivations. When and if this is the case, quantitative assessments of device choice may go astray, if not supplemented by qualitative consideration. One good example from the material at hand is the quota arrangements of the feudal Legislative Assembly of the Kingdom of Tonga, which requires the Cabinet ministers, who are nominated by the King, to sit in the House ex officio and also recognizes nine hereditary nobles, elected by their own class. Obviously, these arrangements are about the preservation and concentration of power rather than devolution of power (Lawson, 1996:90-96). Second, policy-making processes are less complex in small countries than in larger countries (Dahl \& Tufte, 1973:35-40). They therefore require a less developed set of institutions, meaning that a device for the advancement of some specific goal need not in a small system be completed and backed up with supplementing and overlapping arrangements. Devolution strategies may then be implemented through one rather than many conceivable institutional channels. Again, therefore, device counting may go astray if not supplemented by qualitative observation.

\section{References}

Anckar, C., Eriksson, M. \& Leskinen, J. (2002) Measuring Ethnic, Linguistic and Religious Fragmentation in the World, Occasional Papers Series, No. 18, Åbo, Department of Political Science, Åbo Akademi University.

Anckar, D. (1998) 'Bicameral Microstates: A Commonwealth Category', The Round Table: Commonwealth Journal of International Affairs, Issue 347, pp. 367-378.

Anckar, D. (2002) 'Why are Small Island States Democracies?', The Round Table: Commonwealth Journal of International Affairs, Issue 365, pp. 375-390.

Anckar, D. (2003) 'Lilliput Federalism: Profiles and Varieties', Regional \& Federal Studies, Vol. 13, No. 3, pp. 107-124.

Anckar, D. (2004) 'Regime Choices in Microstates: The Cultural Constraint', Journal of Commonwealth \& Comparative Politics, Vol. 42, No. 2, pp. 206-223.

Anckar, D. (2005) 'Decentralization and Island Nationalism in Microstates: Where, How and Why?', Canadian Review of Studies in Nationalism, Vol. 32, Nos. 1-2, pp. 109-120.

Anckar, D. (2006) 'Assembly Quotas in Microstates', Parliaments, Estates \& Representation, Vol. 26, pp. 197-210. 
Anckar, D. \& Bartmann, B. (2000) Ett ramverk för ett självständigt Åland, Mariehamn, Sällskapet Ålands framtid.

Baldacchino, G. (2000) 'The Challenge of Hypothermia', The Round Table: Commonwealth Journal of International Affairs, Issue 353, pp. 65-79.

Baldacchino, G. (2006) 'Islands, Island Studies, Island Studies Journal', Island Studies Journal, Vol. 1, No. 1, pp. 3-18.

CIA The World Factbook, Washington DC. Central Intelligence Agency, www.cia.gov/cia/publications/factbook/index.html.

Dahl, R.A. \& Tufte, E.R. (1973) Size and Democracy, Stanford, Stanford University Press.

Derbyshire, J.D. \& Derbyshire, I.D. (1999) Political Systems of the World, Oxford, Helicon Publishing.

Diamond, L. \& Tsalik, S. (1999) 'Size and Democracy: The Case for Decentralization' in L. Diamond (ed.) Developing Democracy: Toward Consolidation, Baltimore, Johns Hopkins University Press, pp. 117-160.

Duursma, J. (1994) Self-Determination, Statehood and International Relations of MicroStates, Leiden, University of Leiden.

Easton, D. (1965) A Systems Analysis of Political Life, New York, John Wiley \& Sons.

Gottmann, J. (1980) 'Spatial Partitioning and the Politician's Wisdom', International Political Science Review, Vol. 1, No. 4, pp. 432-455.

Hague, R. \& Harrop, M. (2004) Comparative Government and Politics, $6^{\text {th }}$ Edition, Hampshire, Palgrave Macmillan.

Hamilton-Jones, D. (1992) 'Problems of Inter-Island Shipping in Archipelagic Small Island Countries: Fiji and the Cook Islands' in H.M. Hintjens \& M.D.D. Newitt (eds.) The Political Economy of Small Tropical Islands, Exeter, University of Exeter Press, pp. 200222.

Hartmann, C. (2001) 'Fiji Islands' in D. Nohlen, F. Grotz \& C. Hartmann (eds.) Elections in Asia and the Pacific, Oxford, Oxford University Press, pp. 643-672.

Hawthorne, W. (1999) 'Republic of Cape Verde' in D.A. Kaple (ed.) World Encyclopedia of Political Systems and Parties, Vol. I, $3^{\text {rd }}$ edition, New York, Facts on File, pp. 186-187.

Henningham, S. (1995) The Pacific Island States: Security and Sovereignty in the PostCold War World, New York, St. Martin’s Press. 
Hodges, T. \& Newitt, M.D.D. (1988) Sao Tomé and Príncipe: From Plantation Colony to Microstate, London, Westview Press.

Htun, M. (2004) 'Is Gender Like Ethnicity? The Political Representation of Identity Groups’, Perspectives on Politics, Vol. 2, No. 3, pp. 439-458.

Karvonen, L. (2003) Statsskick: Att bygga demokrati, Stockholm, SNS Förlag.

Laponce, J. \& Saint-Jacques, B. (1997) 'Introduction: Institutions as Problem-Solvers', International Political Science Review, Vol. 18, No. 3, pp. 233-236.

Lawson, S. (1996) Tradition versus Democracy in the South Pacific: Fiji, Tonga and Western Samoa, Cambridge, Cambridge University Press.

Legg, K. (1999) 'Republic of Cyprus' in D.A. Kaple (ed.) World Encyclopedia of Political Systems and Parties, Vol. I, $3{ }^{\text {rd }}$ edition, New York, Facts on File, pp. 269-273.

Lijphart, A. (1977) Democracy in Plural Societies: A Comparative Exploration, Berkeley CA, University of California Press.

Lijphart, A. (1999) Patterns of Democracy. Government Forms and Performance in Thirty-Six Countries, New Haven CT, Yale University Press.

LiPuma, E. (1995) 'The Formation of Nation-States and National Cultures in Oceania' in R. J. Foster (ed.) Nation Making. Emergent Identities in Postcolonial Melanesia, Ann Arbor MI, University of Michigan Press, pp. 33-68.

Merrit, R.L. (1969) 'Noncontiguity and Political Integration' in J.N. Rosenau (ed) Linkage Politics, New York, Free Press, pp. 237-272.

Morgenthau, H. (1966) Politics among Nations, 4th edition, New York, Alfred A. Knopf.

Ott, D. (2000) Small is Democratic: An Examination of State Size and Democratic Development, New York, Garland.

Ravuvu, A. (1992) 'Culture and Traditions: Implications for Modern Nation Building' in R. Crocombe, U. Neemia, A. Ravuvu \& W. vom Busch (eds.) Culture \& Democracy in the South Pacific, Suva, Institute of Pacific Studies, University of the South Pacific, pp. 57-66.

Richardson, B.C. (1992) The Caribbean in a Wider World: 1492-1992, Cambridge, Cambridge University Press.

Royle, S.A. (2001) A Geography of Islands: Small Island Insularity, London, Routledge. 
Short, I. (1987) 'The Cook Islands: Autonomy, Self-Government and Independence’ in A. Hooper, S. Britton, R. Crocombe, J. Huntsman \& C. Macpherson (eds.) Class and Culture in the South Pacific, Centre for Pacific Studies, University of Auckland, pp. 176-184.

So’o, A. (2001) 'Samoa' in D. Nohlen, F. Grotz \& C. Hartmann (eds.) Elections in Asia and the Pacific, Oxford, Oxford University Press, 779-794.

Srebrnik, H.F. (2004) 'Small Island Nations and Democratic Values', World Development, Vol. 32, No. 2, pp. 329-341.

Virelala, J-P. (1995) 'To be a Francophone in Vanuatu’ in H. Van Trease (ed.) Melanesian Politics. Stael Blong Vanuatu, Christchurch, New Zealand, Macmillan Brown Centre for Pacific Studies, University of Canterbury, pp. 403-406. 